bosis did not improve as formerly and residual pain, though not troublesome, still remained in the following June.

The above case seems to be the first in which ancrod has been given in repeated courses. Antibody formation, investigated by radioimmunoassay after the fifth course, was negligible. Hydrocortisone may have played some part in this because it is known that corticosteroids can suppress antibody formation under some conditions." In this patient the most useful benefit appears to be in reducing the incidence of thromboembolism after the ancrod therapy. Our evidence for this is based on the number of thromboembolic incidents pre- and post-ancrod administration. Though this point has not been established with certainty, it could, if confirmed, prove a valuable addition to our anticoagulant therapy.

Nicholas G Kounis

East Birmingham Hospital

Chest Branch,

Birmingham

W Howel Evans

Walton Hospital,

Rice Lane,

' Kounis, N G, MD Thesis, Athens University, 1976.

2 Kounis, N G, and Evans, W H, Angiology, 1976. In

press.
Reid, H A, and Chan, K E, Lancet, 1968, 1, 485.

Fearnley, G R, Chakrabarti, R, and Hocking, E D, Lancet, 1967, 2, 1008.

Fearnley, G R, Chakrabarti, R, and Evans, G F Lancet, 1969, 1, 617

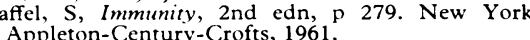

\section{Acupuncture analgesia}

SIR,-Mr D Stewart and his colleagues (8 January, p 67) do not mention whether, in the techniques they used to achieve acupuncture analgesia, "techi" had been experienced. This is the area in muscle proprioceptors where the needle must engage for maximal effect. It is the basis of the "needle test" used on patients in China a day or so before their operation. When I attended an analgesic clinic in a hospital in Taiwan both physician and patient were dissatisfied unless "techi" had been experienced. The sensation is a peculiar and characteristic one of numbness and distension. I found it to be distinctly unpleasant, but from the point of view of analgesia it is considered critical.

It seems to me that this could complicate a "controlled" trial since the patient's conscious acknowledgement that "techi" has been gained is essential.

FRANK S RICKARDS

Great Sutton,
Wirral, Cheshire

\section{Placental transfer of IgG paraprotein} with prolonged immunosuppression

SIR,-In 1970 we reported the transfer across the placenta of a maternal IgG paraprotein which gave rise to suppression of the circulating concentrations of $\operatorname{IgG}, \operatorname{IgA}$, and $\operatorname{IgM}$ in the infant. ${ }^{1}$ The IgG and IgA concentrations were still low at two years. We report here the progress of child and mother during the subsequent seven years.

During the past four years the boy, who is now 9 years old, has had attacks of wheezing lasting $36 \mathrm{~h}$ or so four or five times a year, usually following close contact with cats or grasses. Skin testing confirmed allergies to cat dander and grass pollens. He has been otherwise well and has shown no increased susceptibility to infections. The mother has remained symptom-free and she too has shown no increased susceptibility to infections.

The boy shows no remaining abnormality of immunoglobulin concentration. The mother's monoclonal paraprotein of IgG type $\kappa$ has persisted but has shown no change in concentration (total IgG concentration $31 \mathrm{~g} / \mathrm{l}$ ). There has been no significant change in the concentration of $\operatorname{IgA}$ or $\operatorname{IgM}$ and there is no Bence Jones proteinuria. Thus it now appears that the monoclonal IgG which was transferred across the placenta from the mother in high concentration and caused prolonged suppression of humoral immunity was benign. The suppression has not persisted and has caused no lasting ill effects.

J M LitTlewood R B PAYNE

St James's University Hospital

Littlewood, J M, et al, British Medical fournal, 1970,

Laparoscopy and hysterosalpingography as tests of tubal patency

SIR,-I agree with Dr O A Ladipo (27 November, p 1297) that there is no doubt that laparoscopy offers a better assessment than hysterosalpingography of tubal pathology, especially in the ampullary region and when there are peritoneal adhesions. Also pocketing of the dye seen by hysterosalpingography in cases of tubo-ovarian masses can be confirmed by laparoscopy. But I do not think that ?aparoscopy could replace hysterosalpingography in cases of cornual block when a small portion of the cornual part of the tube is patient and reimplantation or recanalisation could be done. Also laparoscopy is not capable of visualising diverticulosis of the tubes seen in chronic infection or tuberculosis. Again, in some cases of bilharzial or tuberculous granulomas in which only a small portion of the tube is involved in the lesion causing obstruction and the rest of the tube is functional hysterosalpingography is useful in visualising the site of obstruction.

We are planning a report on tubal disease as evidenced by hysterosalpingography and laparoscopy in the near future. Meanwhile we consider that laparoscopy is complementary to hysterosalpingography rather than a replacement for the study of tubal pathology.

\section{Medical City,}

Baghdad, Iraq

\section{Hospital practitioner grade}

SIR,-The letter from Mr G Wilmot (22 January, p 235) on the hospital practitione grade is part of the proper and healthy political debate which is taking place about the future of this grade. The general debate continues in the Central Committee for Hospital Medical Services, the General Medical Services Committee, and the Joint Consultants Committee, and will no doubt at some stage involve the Council of the BMA and the Representative Body itself.
I write now, however, only to comment on one area of concern expressed by $\mathrm{Mr}$ Wilmo -a concern shared by many hospital doctors. He refers to the statement in paragraph 25 of the Review Body's Sixth Report in which it was assumed "...that work of a more responsible nature would be involved than in either the medical assistant and assistant dental surgeon grade or in the part-time medical and dental officer grade."

The facts are that the Review Body had made a false assumption and I, too, have been unable to discover the exact source of this misunderstanding. Nothing, however, in either the written or oral evidence from the BMA to the Review Body would support this assumption and at a recent meeting with the Review Body the assumption was clearly refuted on behalf of the Association and the position clarified.

The fact is that there is no direct relationship between the degree of responsibility to be exercised by medical assistants, clinical assistants, or hospital practitioners-that is, some medical assistants and some clinical assistants will be more experienced and bear more responsibility than some hospital practitioners and vice versa. Among general practitioners working in hospital, however, it is likely that those who are graded (or eligible to be graded) as hospital practitioners will be more experienced than those who are clinical assistants.

Although I have been unable to discover the source of this misunderstanding, I am convinced that the Review Body now appreciates the situation quite clearly and I trust that this statement clarifies the position, as I am well aware that this error has led to considerable concern throughout the profession. In confining my reply to this one aspect of Mr Wilmot's letter, I recognise that many areas of concern surrounding the hospital practitioner grade remain, and I assure him that the CCHMS is well aware of these problems and will continue to seek fair and sensible solutions.

A H GrabhaM

Central Committee for Hospital Medical Services

BMA House

Tavistock Square
London WC1

\section{Ethical responsibilities of NHS doctors}

SIR, - The report of the joint working party on the ethical responsibilities of doctors practising in the National Health Service (15 January, p 157) is confused and contradictory.

"The profession," says the working party, "should not require the State to renegue on its social responsibilities," but what do they mean by "the profession" and "the State"? "The profession" is the sum of its members. the doctors. "The State" has an abstract air, but in practice it consists of the Government of the day and the apparatus at its disposal. The Government in its turn consists of Ministers of the Crown, but in practice they are members of Parliament, which they have become only by being committed to a particular political party. They are not impartial; if they were they would not be members of Parliament. They determine the "social responsibilities" of the State and politicians of the left would not agree with those of the right on an interpretation of those responsibilities. 